\title{
Obesitas Surgery Can Cure More than Obesitas Alone. Contact Can Change a World
}

\section{Ferdinand Schreuder*}

General Practitioner, Delft, The Netherlands

Keywords: Astma; Aggression-regulation-disorder; Aggression

\section{Case Report}

When he first came into our practice, we all were somewhat afraid of the Very Fat Man. He had moved in our area and we had the "honour" to be his general practitioners.

His file showed diagnosis "astma" and "aggression-regulationdisorder" and he had plenty medication to alleviate his symptoms: $2 \times 25 \mathrm{mcg}$ salmeterol, $4 \times 400 \mathrm{mcg}$ salbutamol, $3 \times 40 \mathrm{mcg}$ ipratropium and $2 \times 250 \mathrm{mcg}$ fluticason. One or two times a year he suffered an exacerbation but stop smoking was impossible to him, because he would get more aggressive, as he said. Once a psychiatrist dismissed him with high doses of benzodiazepines, which he took for years; now he takes every day: $2 \times 50 \mathrm{mg}$ oxazepam and $2 \times 2 \mathrm{mg}$ flunitrazepam and this dose seemed indeed to prevent burst-outs, as his wife told me once. His aggression, he told me, ("stress-reaction" as he called it) was rooted in the very severe illness of his first child in her first year of life (1991). However, already in 1981, when his weight was only $107 \mathrm{~kg}$, he was prescribed with small doses of benzodiazepines quite often.

Gradually his morbid adipositas prevented any outdoor activity and for years, he could not do anything but sitting on the floor (since no chair was able to hold his $256 \mathrm{~kg}$ ). This inactivity enhanced his weight-gain and his smoking. For several years, it was thought that, his case was hopeless, so no way was found to improve his life. It was rather anger than "a professional distance" that characterised my attitude to him. During a home-visit for another exacerbation, the man was seen with his neglected body, sitting on the messy floor of the living room, full ashtray on the table, asking for some antibiotics. This lifestyle would surely be lethal, sooner rather than later.

Now - 5 years later- he tells me that this moment was a turning point for him: only then, he realized the danger he was in. Two weeks later, he came to the clinic to discuss possibilities for change. This resulted in referral for obesitas-surgery and all the medical care that was needed before and after. Several operations later, he had lost $>150 \mathrm{~kg}$ and he keeps his weight stable now with diet for more than two years.

He got regular work, quitted smoking and feels much better.

He stopped the asthma medication (which he had used for more than 25 years) without any problem. He gradually stopped his benzodiazepines in a few months (with some outbursts of aggression indeed) and is now not disturbing his family anymore with his bad moods or violence. His wife told me that he has changed and his violence had disappeared for years now. This year he will get 50 years with many scars but a proud mind.

There is a well-known association between obesitas and asthma [1] and improvement of asthma after bariatric surgery has been reported before [2,3], but this improvement in my patient does probably also result from stop-smoking. The improvement in his psycho-social functioning is also striking, but not altogether unexpected [4,5].

Most astonishing was the way all this improvement started: the contact that was made by expressing caring feelings might have helped this patient to change.

This patient taught us how surgery might cure behavioural problems and to keep courage.

\section{References}

1. Shore SA (2008) Obesity and asthma: possible mechanisms. J Allergy Clin Immunol 121: 1087-1093.

2. Brancatisano WS, Brancatisano R (2008) Improvement in comorbid illness after placement of the Swedish Adjustable Gastric Band. Surg Obes Relat Dis 4: S39-46.

3. Simard TH, Marceau P, Biron S, Hould FS, Lebel S, et al. (2004) Asthma and sleep apnea in patients with morbid obesity: outcome after bariatric surgery. Obes Surg 14: 1381-1388.

4. van Hout GC BP, Fortuin FA, Pelle AJ, van Heck GL (2006) Psychosocia functioning following bariatric surgery. Obes Surg 16: 787-794.

5. Sarwer DB, Fabricatore AN (2008) psychiatric considerations of the massive weight loss patient. Clin Plast Surg. Clin Plast Surg 35: 1-10. *Corresponding author: Ferdinand Schreuder, Handellaan 108-D, 2526 SN Delft,
The Netherlands, E-mail: schr0095@planet.nl

Received May 20, 2013; Accepted June 18, 2013; Published June 21, 2013

Citation: Schreuder F (2013) Obesitas Surgery Can Cure More than Obesitas Alone. Contact Can Change a World. J Gen Pract 1: 108. doi: 10.4172/23299126.1000108

Copyright: (c) 2013 Schreuder F. This is an open-access article distributed under the terms of the Creative Commons Attribution License, which permits unrestricted use, distribution, and reproduction in any medium, provided the original author and source are credited. 